\title{
Molecular Epidemiology of KPC-2 Producing Klebsiella pneumoniae
}

\author{
Cristina Motta Ferreira ${ }^{1}$, William Antunes Ferreira ${ }^{2}$, Lucyane Mendes Silva ${ }^{3}$, Thiago Costa
} Barbosa $^{4}$, Victor Costa De Souza ${ }^{3}$ and Felipe Gomes Naveca ${ }^{3}$

${ }^{1} \mathrm{PhD}$ in Tropical and Infectious Disease. Fundação de Hematologia e Hemoterapia do Amazonas -HEMOAM, Brasil

${ }^{2}$ PhD in Tropical and Infectious Disease. Fundação de Dermatologia Tropical e Venereologia Alfredo da Matta- FUAM, Brasil

${ }^{3}$ Fellowship of FAPEAM. Fundação de Hematologia e Hemoterapia do Amazonas -HEMOAM, Brasil

${ }^{4}$ Fellowship of Master Science in Science Applied in Haematology. Fundação de Hematologia e Hemoterapia do Amazonas -HEMOAM, Brasil

${ }^{5}$ Master in Tropical Patology. Instituto Leônidas e maria Deane-FIOCRUZ-Amazonia, Brasil

${ }^{6}$ PhD in Microbiology. Instituto Leônidas e Maria Deane-FIOCRUZ-Amazonia, Brasil

Received: 01 June, 2017; Accepted: 03 July, 2017; Published: 14 July, 2017

*Corresponding author: Cristina Motta Ferreira, PhD in Tropical and Infectious Disease, Fundação de Hematologia e Hemoterapia do Amazonas-HEMOAM. Av. Constantino Nery, 4327. Chapada. CEP: 69055-002. Manaus- Amazonas, Brasil. Tel: 55-92-36550139;E-mail: cris_motta_ferr@ yahoo.com.br

\begin{abstract}
We describe the molecular epidemiology of the KPC-2 K. pneumoniae among public hospitals in the Amazon State, Brazil. A total of $4.4 \%$ (5/113) of the K. pneumoniae isolates were identified as KPC-producing and CTX-M-109 beta-lactamase. Further, MultiLocus Sequence Typing identified three clones STs11, 40 and 2230. To the best of our knowledge, the present study demonstrates for the very first time, detection of the multidrug resistant K. pneumoniae (KPC2), ST2230 clone, in Brazil.
\end{abstract}

Keywords: ST2230; CTX-M-109; Carbapenem Resistance; Antimicrobial; Multi Resistant

\section{Text}

Nosocomial infections caused by carbapenemaseproducing bacteria has increased worldwide and have become a serious public health threat [1]. Infections resulting from this pathogen may lead to a serious life-threatening illness [2] and are characterized by a resistant phenotypic profile to monobactams, carbapenems, broad spectrum cephalosporins, fluoroquinolones and aminoglycosides [2-4]. These bacteria pose a significant risk for hospitalized patients, particularly for neonates, immune-compromised, diabetics or patients with alcohol-associated disorders or bloodstream infections, as well as those receiving advanced medical care [2,3]. The antibiotic therapies available to treat these infections are restricted to tigecycline, polymyxins and occasionally aminoglycosides [3,5]. A number of KPC variants have been described among which the KPC-2 and -3 are the most prevalent [3,5]. In this study, we described the molecular epidemiology of five KPC- producing K. pneumoniae among public hospitals in the Amazon region. In the year 2015, a total of 133 clinical samples of $K$. pneumoniae were obtained from inpatients from two public hospitals in Manaus-Brazil. The biochemical identification and susceptibility test of these isolates were performed by VITEK-2 automated system protocols (bioMérieux, France). The screening detection for Extended-Spectrum B-Lactamase (ESBL) and for carbapenemase production were performed according to CLSI (2015) recommendations [6]. Plasmid DNA was extracted with the use of PureLink ${ }^{\mathrm{TM}}$ Quick Plasmid Miniprep Kit (INVITROGEN, CARLSBAD, CA, USA). Further, molecular analysis was performed by Polymerase Chain Reactions (PCRs). PCR amplifications

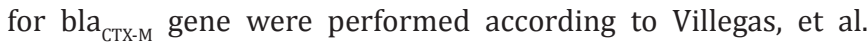
[7]. For carbapenemase production $\left(\mathrm{bla}_{\mathrm{KPC}}\right)$, we designed one pair of primers (bla $\mathrm{KPC} \mathrm{FW}-5^{\prime}$-ATGTCACTGTATCGCCGTC-3') and $\left(\mathrm{bla}_{\mathrm{KPC}} \mathrm{RV}-5^{\prime}\right.$-TTACTGCCCGTTGACGCC-3'). For bla ${ }_{\mathrm{NDM}}$ production gene, we designed another pair of primers (bla ${ }_{\mathrm{NDM}} \mathrm{FW}-5^{\prime}$ - GCCCAATATTATGCACCCGG-3'); (bla ${ }_{\mathrm{NDM}} \mathrm{RV}-5^{\prime}$ CGCAGCTTGTCGGCCAT- $3^{\prime}$ ). The sequencing of the bla $_{\mathrm{KPC}}$ and bla $_{\mathrm{NDM}}$ amplicons were performed at ABI 3130 sequencer, (Applied Biosystems, Foster City, CA). These sequences were analyzed with a software geneious V.10.0.10. Multilocus Sequence Typing was performed according to Institut Pasteur's MLST scheme (http://bigsdb.web.pasteur.fr. ) and for bla ${ }_{\text {CTX-M }}$ gene, the blastn was made (http://blast.ncbi.nlm.nih.gov/Blast.cg ). The total of the 113 isolates of the K. pneumoniae were obtained from different biological sites such as urine $44.2 \%$ (50/113), blood $30 \%$ (34/113), tracheal aspirate $20.3 \%$ (23/113), wound $1.76 \%$ $(2 / 113)$ and fecal $0.88 \%(1 / 113)$. The susceptibility test of them showed resistance of $100 \%$ to ceftriaxone and cefepime; $69.9 \%$ 
(79/113) to gentamicin; $64.6 \%$ (73/113) to ciprofloxacin; $60.1 \%$ (68/113) to ceftazidime; $54.8 \%(62 / 113)$ to cefoxitin, and $4.4 \%$ (5/113) to tigecycline. Five of the $113 \mathrm{~K}$. pneumoniae isolates $4.4 \%$ (5/113), showed MICs to ertapenem of $\geq 8 \mu \mathrm{g} / \mathrm{mL}$, meropenem $\geq$ $8 \mu \mathrm{g} / \mathrm{mL}$ and $16 \mu \mathrm{g} / \mathrm{mL}$, and to imipenem $4 \mu \mathrm{g} / \mathrm{mL}, 8 \mu \mathrm{g} / \mathrm{mL}$ and $16 \mu \mathrm{g} / \mathrm{mL}$. These five isolates presented also susceptibility to amikacin, two of them to tigecycline, and three to colistin. They were identified as ESBL and KPC-producing bacteria, and were isolated from blood $(2 / 5)$, urine $(1 / 5)$ and tracheal aspirate $(2 / 5)$, from five patients admitted at the intensive care unit, three of them were male $(22,42,65$ years-old), one female (30 yearsold), and one newborn. The obtained sequence of the bla СTX-м $_{\text {gene }}$ showed similarity with CTX-M-109, and the sequence of the bla ${ }_{\mathrm{KPC}}$ plasmidial gene showed identity with the sequence of $\mathrm{bla}_{\mathrm{KPC}-2}$ We didn't find the presence of bla ${ }_{\mathrm{NDM}}$ plasmidial gene. The MLST analysis showed that these five KPC-producing isolates belonged to the ST11(1/5), ST340 (3/5) and ST2230 (1/5). The ST2230 was identified as a new clone, in the Amazon Brazilian region (GenBank accession: KY689923; KY689924; KY689925). Two of the KPC-producing isolates not deposited at the GenBank, had the identical sequence of bla $_{\mathrm{KPC}-2}$ gene and were the same clone (ST340). Multidrug resistant bacteria are a substantial threat to public health because their resistance to all the antibiotic options available, and the most serious infections occurs in health care settings caused by K. pneumoniae [8]. Concerned with this problem, the World Health Organization (WHO) developed a global priority pathogens list, in which $K$. pneumoniae is at the priority one (critical) (http://www.who.int/medicines/ publications/global-priority-list-antibiotic-resistant-bacteria/ en/ ). The endemic dissemination of the carbapenemase variant KPC- 2 and KPC-3, has been reported in the USA (5.7\%), Italy (89.5\%), Canada (89.3\%), and China (63\%) [9-12]. The ST258 clone, predominant in European countries, has contributed significantly to the worldwide distribution of the carbapenem resistance [4]. In Asia, there are different clones such as ST392 and ST395, which also harbor the bla $\mathrm{KPC}-2_{2}$ gene, whereas in Brazil, different STs such as ST437, ST340 and ST842, harboring the KPC-2 variant, have been described and isolated from different healthcare settings $[12,13]$. The spread of the antibiotic resistance genes maybe be associated with the dissemination of clones, and other factors such as plasmids, and transposons - i.e. Horizontal Gene Transfer (HGT) - between bacteria [4,14,15]. Furthermore, the capacity of the K. pneumoniae to colonize medical equipment and to survive for long periods of time, at extreme temperature in the environment, explains why this pathogen can also be isolated from hospital environment and play an important role in the horizontal transfer of antibiotic resistance, acting also as an efficient donor and receptor [4,13,16-19]. The events observed in the present study, suggest that asymptomatic carriers, such as health professionals and their flow between different hospitals; patient or other people who move through hospitals, may be contributing to the local dissemination of these clones, which may affect vulnerable patients [13]. The ST11 and ST340 clones were isolated from inpatients at the same general hospital. These clones were observed in different states of Brazil such as Ceará, Pernambuco, Rio de Janeiro, Piauí, Alagoas and Federal District
[13]. To date, only one clone (ST841) was described in Manaus, Amazonas [13]. The ST2230 clone, that has been described before in China, was isolated from a blood sample of a newborn from a maternity hospital, being the first description in the city and in Brazil, and possibly representing an important fact, once it is associated with multidrug resistance. Pereira, et al. detected resistant clones to carbapenems, amikacin, tigecycline and colistin [13]. In the present study, the clones were sensitive to colistin and to amikacin. Since the KPC-producing bacteria present a resistance profile to different classes of antibiotics, such as monobactams, carbapenems and broad spectrum cephalosporins, the last therapeutic options that remain is polymyxin B, colistin and fosfomycin $[3,13,19]$. A serious prophylactic action in the health centers with focus on control measure of the environment, contact precautions, hand hygiene, early identification of asymptomatic carriers, antimicrobial stewardship and the implementation of the infection control guideline, are obligatory to prevent, control or at least to reduce the risks of dissemination of those virulent clones [20]. Preventive measures are necessary to avoid the dissemination of these highly pathogenic clones among hospitals and KPC producing K. pneumoniae positive patients, should be isolated and treated according standard guidelines.

\section{Acknowledgments}

We thank the team of the curators of the Institut Pasteur MLST system (Paris, France) for importing novel alleles, profiles and/or isolates at http://bigsdb.web.pasteur.fr

\section{References}

1. Corbellini S, Caccuri F, Gelmi M, De Francesco MA, Fiorentini S, Caruso A, et al. Emergence of carbapenem-resistant Klebsiella pneumoniae strains producing KPC-3 in Brescia Hospital, Italy. New Microbiol. $2014 ; 37(2): 177-183$

2. Siu LKK, Huang DB, Chiang T. Plasmid transferability of KPC into a virulent K2 serotype Klebsiella pneumoniae. BMC Infectious Disease. 2014;14:176-182.

3. Girmenia C, Serrao A, Canichella M. Epidemiology of carbapenem resistant Klebsiella pneumoniae infections in Mediterranean countries. Mediterr J Hematol Infect Dis. 2016;8(1):e2016032. doi: 10.4084/ MJHID.2016.032

4. Pitout JDD, Nordmann P, Poirel L. Carbapenemase-producing Klebsiella pneumoniae, a key pathogen set for global nosocomial dominance. Antimicrob Agents Chemother. 2015;59(10):5873-84. doi: 10.1128/ AAC.01019-15

5. Akturk H, Sutcu M, Somer A, Aydın D, Cihan R, Ozdemir A, et al. Carbapenem-resistant Klebsiella pneumoniae colonization in pediatric and neonatal intensive care units: risk factors for progression to infection. Braz J Infect Dis. 2016;20(2):134-140. doi: 10.1016/j. bjid.2015.12.004

6. Clinical and Laboratory Standards Institute. Performance Standards for Antimicrobial Susceptibility Testing; 25th Information Supplement M100-S25, CLSI, Wayne. 2015:240.

7. Villegas MV, Correa A, Federico P, Zaluaga T, Radice M, Gutkind G, et al. CTX-M-12-Beta-Lactamase in a Klebsiella pneumoniae Clinical Isolate 
in Colombia. Antimicrob Agents Chemother. 2004;48(2):629-631.

8. Ventola CL. The Antibiotic Resistance Crisis. Part 1: Causes and Threats. P T. 2015;40(4):277-83.

9. Woodford N, Turton JF, Livermore DM. Multiresistant Gram-negative bacteria: the role of high-risk clones in the dissemination of antibiotic resistance. FEMS Microbiol Rev. 2011;35(5):736-755. doi: 10.1111/j.1574-6976.2011.00268.x

10.Fehlberg LCC, Carvalho AMC, Campana EH, Gontijo-Filho PP, Gale AC. Emergence of Klebsiella pneumoniae-producing KPC-2 carbapenemase in Paraíba, Northeastern Brazil. Braz J Infect Dis. 2012;16(6):577-580.

11. Giani T, Pini B, Arena F, Conte V, Bracco S, Migliavacca R, et al. Epidemic diffusion of KPC carbapenemase-producing Klebsiella pneumoniae in Italy: results of the first countrywide survey, 15 May to 30 June 2011. Euro Surveill. 2013;18(22). pii: 20489.

12. Lee CR, Lee JH, Park KS, Kim YB, Jeong BC, Lee SH. Global Dissemination of Carbapenemase-Producing Klebsiella pneumoniae: Epidemiology, Genetic Context, Treatment Options, and Detection Methods. Front Microbiol. 2016;7:895. doi: 10.3389/fmicb.2016.00895

13.Pereira PS, de Araujo CF, Seki LM, Zahner V, Carvalho-Assef AP, Asensi MD. Update of the molecular epidemiology of KPC-2-producing Klebsiella pneumoniae in Brazil: spread of clonal complex 11 (ST11, ST437 and ST340). J Antimicrob Chemother. 2013;68(2):312-316. doi: $10.1093 / \mathrm{jac} / \mathrm{dks} 396$

14. Nordmann P, Cuzon G, Naas T. The real threat of Klebsiella pneumoniae carbapenemase producing bacteria. Lancet Infect Dis. 2009;9(4):228236. doi: 10.1016/S1473-3099(09)70054-4
15. Pesesky MW, Hussain T, Wallace M, Wang B, Andleeb S, Burnham CD, et al. KPC and NDM-1 Genes in Related Enterobacteriaceae Strains and Plasmids from Pakistan and the United States. Emerging Infectious Diseases. 2015;21(6):1034-1037.

16. García-Fernández A, Villa L, Carta C, Venditti C, Giordano A, Venditti $\mathrm{M}$, et al. Klebsiella pneumoniae ST258 Producing KPC-3 Identified in Italy Carries Novel Plasmids and OmpK36/OmpK35 Porin Variants. Antimicrob Agents Chemother. 2012;56(4):2143-5. doi: 10.1128/ AAC.05308-11

17. Silva RM, Traebert J, Galato D. Klebsiella pneumoniae carbapenemase (KPC)-producing Klebsiella pneumoniae: a review of epidemiological and clinical aspects. Expert Opin Biol Ther. 2012;12(6):663-671. doi: 10.1517/14712598.2012.681369

18. Munoz-Price LS, Poirel L, Bonomo RA, Schwaber MJ, Daikos GL, Cormican $\mathrm{M}$, et al. Clinical epidemiology of the global expansion of Klebsiella pneumoniae carbapenemases. Lancet Infect Dis. 2013;13(9):785-796. doi: 10.1016/S1473-3099(13)70190-7

19. Tacão M, Correia A, Henriques IS. Low Prevalence of CarbapenemResistant Bacteria in River Water: Resistance Is Mostly Related to Intrinsic Mechanisms. Microb Drug Resist. 2015;21(5):497-506. doi: 10.1089/mdr.2015.0072

20.Thomas CP, Moore LSP, Elamin N, Doumith M, Zhang J, Maharjan S, et al. Early (2008-2010) hospital outbreak of Klebsiella pneumoniae producing OXA-48 carbapenemase in the UK. Int J Antimicrob Agents. 2013;42(6):531-6. doi: 10.1016/j.ijantimicag.2013.08.020 